\title{
The invasion of plant communities following extreme weather events under ambient and elevated temperature
}

\author{
Christine S. Sheppard · Jake M. Alexander • \\ Regula Billeter
}

Received: 15 November 2011 / Accepted: 20 June 2012/Published online: 7 July 2012

(C) Springer Science+Business Media B.V. 2012

\begin{abstract}
Although the problem of plant invasions is expected to increase with climate change, there is as yet little experimental evidence, in particular, for the effects of extreme weather events. We established communities of European meadow species, which were subjected to warming and extreme event (drought and deluge) treatments in a factorial design at an experimental garden in Zurich, Switzerland. Phylogenetically matched pairs of native and alien species (Bromus erectus, B. inermis, Trifolium pratense, T. hybridum, Lactuca serriola, and Conyza canadensis) were introduced into the communities to test if invader performance is favored by warming and extreme events, and if alien invaders perform better than native colonizers. With a warming of on average
\end{abstract}

Electronic supplementary material The online version of this article (doi:10.1007/s11258-012-0086-5) contains supplementary material, which is available to authorized users.

C. S. Sheppard $(\bowtie)$

School of Biological Sciences, The University of Auckland, Tamaki Campus Building 733, Private Bag

92019, Auckland Mail Centre, Auckland 1142,

New Zealand

e-mail: cjog001@aucklanduni.ac.nz

J. M. Alexander · R. Billeter

Institute of Integrative Biology, ETH Zurich, Universitätsstrasse 16, 8092 Zurich, Switzerland

e-mail: jake.alexander@env.ethz.ch

R. Billeter

e-mail: regula.billeter@env.ethz.ch
$0.3{ }^{\circ} \mathrm{C}$, a higher cover of native plant communities was observed, while drought decreased cover in the short-term and lowered biomass. Germination, survival, and growth of the introduced species were lower under elevated temperature. Survival of all pairs and growth of Trifolium was greater in drought pots, while deluge had no effect. While the alien species showed a faster rate of increase in the number of leaves, mortality of alien species was greater than of native species. Overall, the performance of the focal species varied much more among taxonomic groups than native/alien provenances. The results suggest that with climate change, different types of extreme events will differ in the severity of their effects on native plant communities. Meanwhile, the effects of climate change on plant invasions are more likely to operate indirectly through the impacts on native vegetation.

Keywords Invasive plants - Climate change · Warming · Drought $\cdot$ Flooding ·

Alien-native congeners

\section{Introduction}

Although experimental research into the biological consequences of climate change has been conducted since the 1990s, interest in extreme events is relatively new and has only increased in the past few years, totaling $20 \%$ of climate change studies in 2006 (Jentsch et al. 2007). For the next two decades, a 
global temperature increase of $0.2{ }^{\circ} \mathrm{C}$ per decade is projected across a range of emission scenarios, and precipitation regimes are expected to change (IPCC 2007). The likelihood of some extreme weather events like drought, extreme rainfall, or heat waves will increase, while the likelihood of other extreme events such as frost or extremely cold nights will decrease (IPCC 2007). Most of the severe impacts of climate change may rather be a consequence of changes in the frequency and magnitude of extreme events than of changes in mean values (Nicholls 1995). As individual species respond differently to climate change, each plant community contains some species that will be better adapted to the new conditions. This will lead to changes in interactions, succession, and competitive balance, and consequently long-term changes in the structure and composition of plant communities (Jentsch et al. 2007; Sternberg et al. 1999). However, investigations into the combined effects of extreme events and climatic trends on plant species and communities are rather rare. This is important, however, as net effects cannot be predicted from individual effects when various climatic factors change simultaneously (Le Roux et al. 2005).

Climate change is also expected to affect the spread and colonization of habitats by alien invasive plants (Sutherst 2000). Alien invasive plants are defined as those introduced plants that have established in a new area and are expanding their range (Falk-Petersen et al. 2006). Despite extensive research, few generalizations can be made about the reasons for the success of alien plants, making it difficult to predict how climate change will affect invasion dynamics (Burns 2006; Thuiller et al. 2007). There is evidence that alien invasive species often possess traits that are favored by many aspects of global change (Dukes and Mooney 1999). For example, the possession of a wide ecological amplitude, rapid range shifting, and a lower dependence on outside vectors for pollination and seed dispersal promote rapid responses to climate change and are all typical attributes of invasive species (Vilà et al. 2007). Alien invasive species from a warmer native range could profit from global warming as they are better able to withstand extreme temperature events and mortality decreases with decreasing cold extremes (Vilà et al. 2007). At the same time, the invasion resistance of native communities might be weakened by increased disturbance associated with climate change (Gordon et al. 1999; Thuiller et al. 2007). Disturbance can increase resource availability in a community and damage resident vegetation, thereby opening gaps and decreasing the resource use of resident species (Davis et al. 2000). Accordingly, it has been shown that many kinds of disturbances increase the establishment success of alien plant species (e.g., Petryna et al. 2002). In particular, as many invasive plants are fast-growing ruderals, they are likely to be the first to colonize a disturbed habitat (Truscott et al. 2006). A disturbance such as a drought period may also reduce the vigor of dominant species. Short-term increases in water availability might also promote establishment of alien invasive species (Dukes and Mooney 1999), and even severe floods can provide opportunities to invade because many invasive plants have been shown to re-grow vigorously from small vegetative parts.

Alien invaders might be likely to possess these favorable traits if they are selected by introduction filters, and might be especially successful if they show higher competitive ability and more vigorous growth (Alpert 2006). However, certain native species will also possess these favorable traits. Some researchers argue that in most respects, alien and native expanding species cannot be differentiated functionally and the same processes apply to invasion by alien plants as to colonization by native species (Davis et al. 2000; Davis et al. 2011; Thompson et al. 1995; but see Lambertini et al. 2011). It is therefore not clear to what extent alien species should be favored over native species following climate change.

Only with a better appreciation of interactions between climate change and plant invasions can decisions on minimizing their adverse effects be made. This study aims to contribute to bridging the gap in our knowledge of the effects of elevated temperature and extreme weather events on native communities and on the establishment and performance of invasive species. We simulated elevated temperature and extreme events (drought, deluge) in artificial plant communities, into which phylogenetically matched pairs of native and alien plant species were introduced, to test the following hypotheses: (i) Elevated temperature increases growth of native plant communities, but extreme events decrease growth. (ii) Introduced seedlings (alien and native) perform better under elevated temperature and in native plant communities that have been impacted by 
extreme events. (iii) Alien invader species perform better than native colonizers.

\section{Methods}

Study species

We selected three of the four most abundant alien species in the Swiss Alps (Becker et al. 2005)—Bromus inermis Leyss, Trifolium hybridum L., and Conyza canadensis L. (with 35, 50, and $49 \%$ occurrence in Switzerland, calculated as the number of occupied grid cells of a total of 593 across the country, Laubner and Wagner 2001). B. inermis (Poaceae) is a perennial grass originating from Eurasia, T. hybridum is a perennial legume (Fabaceae) from Eastern Europe, and $C$. canadensis (Asteraceae) is an annual forb from North America. In addition, we selected three related native species which are also common in Switzerland to give three phylogenetically matched pairs of species-Bromus erectus Huds., Trifolium pratense L., and Lactuca serriola L. (with 61,83 , and $27 \%$ occurrence in Switzerland, Laubner and Wagner 2001). Because there are no native Conyza species in Switzerland, L. serriola was chosen as an Asteraceae species, which often appears together with $C$. canadensis in ruderal communities and has a very similar ecology and distribution in Europe (Meusel and Jäger 1992). Seeds of Bromus and Trifolium were obtained from UFA-Samen, Switzerland (with all seeds originally sourced from indigenous populations), and the two Asteraceae species from B and T World Seeds, France. However, owing to the lack of germination of $C$. canadensis and L. serriola, seedlings were sourced from natural populations in Canton Valais. While plants of these species differ from the other species in this respect, this was not of great concern because seedlings within one native-alien species pair originated from the same source. Seedlings of the focal species were grown in a greenhouse $(C$. canadensis 28 days, Trifolium spp. 20 days, L. serriola 14 days, and Bromus spp. 11 days in advance, to achieve similar starting sizes) before introducing them into the pots.

\section{Experimental design}

The experiment was conducted at an experimental garden in Zurich, Switzerland. Seventy-two pots of $70 \mathrm{~L}$ and a surface area of $0.181 \mathrm{~m}^{2}$ with drainage holes $1 \mathrm{~cm}$ above ground level were placed beneath two rainout shelters of $12 \times 5.5 \mathrm{~m}$, with ca. $70-\mathrm{cm}$ spacing between pots. The pots were each filled with $10 \mathrm{~L}$ of expanded clay for drainage, then field soil and on top $8 \mathrm{~L}$ of standard peat-free potting compost to suppress germination of weeds. Each pot contained the same basic plant community, consisting of nine fastgrowing grass (Holcus lanatus L. and Lolium perenne L.), forb (Centaurea jacea L., Crepis biennis L., Leucanthemum vulgare Lam., Plantago lanceolata L., and Prunella vulgaris L.), and legume (Lotus corniculatus L. and Medicago lupulina L.) species that commonly occur in grasslands in Switzerland. They are all montane species found on nutrient rich meadows, flowering between May and September (Laubner and Wagner 2001). Seeds were obtained from UFA-Samen, Switzerland. A total community density of ca. 3,000 mg seeds $/ \mathrm{m}^{2}$ was chosen, to create a community that maximized density and therefore competition while still enabling us to maintain the full species richness in each pot. To divide total number of seeds equally between species, a compromise between maintaining constant seed mass and constant seed number across species was applied (calculated as $\mathrm{y}=\mathrm{a} \times \mathrm{x}^{-0.5 \times \mathrm{b}} \times \mathrm{z} \quad$ (Ramseier, unpublished), where $y$ is the number of seeds per $\mathrm{m}^{2}, x$ is the mass of one seed in $\mathrm{mg}, z$ is the seed density of the whole mixture, and $a$ and $b$ are constants). Seeds were sown in March 2008, but because of a period of cold weather and occasional snow, the first seedlings did not emerge until April 2008. Pots were irrigated daily to provide constant hydrological conditions and they were weeded regularly, but no fertilization was applied. The experiment consisted of fully factorial combinations of the treatments "temperature" (ambient/elevated), "extreme event" (control/drought/deluge), and "focal species" (none/native/alien), giving $2 \times 3 \times$ $3=18$ treatment combinations, which were replicated four times, totaling 72 pots. Treatments were completely randomized within the two rainout shelters (hereafter "blocks").

For the elevated temperature treatment, half of the pots were framed with transparent 0.8 -mm-thick dense plastic open-top cylinders from the start of the experiment. The cylinders reached a height of ca. $35 \mathrm{~cm}$ above the soil and had a radius of $24 \mathrm{~cm}$ (same as the pots). As a result, temperature in the time period from the start of the extreme events until harvest was on average $0.31{ }^{\circ} \mathrm{C}$ higher in pots where plastic foil 
was present. A warming of $0.2{ }^{\circ} \mathrm{C}$ per decade is predicted over the next two decades over a range of emission scenarios (IPCC 2007); the chosen experimental temperature increase therefore corresponds to the climate in 15 years and hence simulates the change expected in the very near future. From seedling emergence to harvest, the treatment resulted in a difference of approximately 36 day-degrees between ambient and elevated temperature pots. Differences were greater at night than during day time when the absolute minimum temperature was on average $0.44{ }^{\circ} \mathrm{C}$ higher in elevated than in ambient temperature pots. Furthermore, elevated temperature pots experienced lower variation than ambient temperature pots (means \pm standard errors of $19.84 \pm 0.04{ }^{\circ} \mathrm{C}$ and $19.53 \pm 0.07{ }^{\circ} \mathrm{C}$, respectively, $F_{1,68}=14.41$, $P<0.001)$. To investigate the influence of the foil on light regimes, photosynthetically active radiation (PAR) was measured above the vegetation in the pots for block one, once on a cloudy and once on a sunny day. Pots with no foil showed a PAR of $258.59 \pm$ $7.08 \mu \mathrm{mol} / \mathrm{m}^{2} \mathrm{~s}$ (cloudy) and $1,103.13 \pm 79.00 \mu \mathrm{mol} /$ $\mathrm{m}^{2} \mathrm{~s}$ (sunny); pots with foil a PAR of $211.07 \pm 4.95$ and $1,234.33 \pm 45.83 \mu \mathrm{mol} / \mathrm{m}^{2}$ s. Differences on a cloudy day were highly significant $\left(F_{1,34}=30.30\right.$, $P<0.001$ ), but not significant on the sunny day $\left(F_{1,34}=2.06, P=0.160\right)$. Average air temperatures during the duration of the experiment were $4.7^{\circ} \mathrm{C}$ (March), $7.9{ }^{\circ} \mathrm{C}$ (April), $15.4{ }^{\circ} \mathrm{C}$ (May), $17.3{ }^{\circ} \mathrm{C}$ (June), $18.4{ }^{\circ} \mathrm{C}$ (July), and $17.7^{\circ} \mathrm{C}$ (August), somewhat higher than the long-term averages $(4.2,7.8,12.1,15.2,17.6$, and $16.7^{\circ} \mathrm{C}$, respectively, for the period 1961-1990; Federal Office of Meteorology and Climatology MeteoSwiss).

The drought treatment was carried out by suspending watering of the pots for 21 consecutive days, starting on 26 May 2008 (for a diagram of the sequence of events see Online Resource 1). This dried the upper ca. $15 \mathrm{~cm}$ of the soil and plants started to wilt. The extreme rainfall ("deluge") treatment was conducted by first sealing the drainage holes, thus allowing only a small amount of water runoff, and then watering these pots daily with $12 \mathrm{~L}$ of water, an equivalent of $16.6 \mathrm{~mm}$ of rain. This was also done for 21 consecutive days during the same period as the drought treatment, resulting in ca. $350 \mathrm{~mm}$ rainfall, the average amount of rainfall in Zurich for all of May, June, and July combined. Control pots continued to be irrigated as before the start of treatments with ca. $3 \mathrm{~L}$ of water per day.
Following extreme events (mid-June 2008, in results and figures referred to as week 0 after extreme events), the focal species treatments were begun. Three seedlings of each of the three native species were planted into one-third of the pots (one of each species near the centre of the pot and two toward the edge). Three seedlings of the three alien species were planted in the second third of the pots, and the remaining third served as a control, i.e., no plants were introduced. Seedlings were transplanted with their root ball intact to minimize disturbance to the seedlings. In addition, for the pots containing introduced seedlings, 50 seeds of each of the three species (either native or alien) were sown into two small areas, separated by $6-\mathrm{cm}$ diameter plastic cylinders to prevent the seeds from being washed away. Introducing both seedlings and seeds allowed us to investigate responses at both germination and juvenile life stages in parallel. With community cover not having reached its full extent (average cover by that time was $67 \%$ ), seedlings could be introduced with minimal disturbance to the plant community, especially as focal species seedlings were small (Trifolium on average $6.8 \mathrm{~cm}$, Bromus $14.9 \mathrm{~cm}$, and the Asteraceae $8.9 \mathrm{~cm}$ tall at the time of introduction). The irrigation and weeding regime was resumed as before the extreme events.

\section{Data collection}

The temperature in each pot was measured using two temperature loggers ("iButtons", Maxim Integrated Products), placed on the soil surface. For the native plant communities, measurements were made before the start of the extreme event treatments, immediately after ("week 0") as well as 2, 4, and 6 weeks later. Community cover was assessed by means of a BraunBlanquet cover scale (Braun-Blanquet 1964). At the end of the experiment (early August 2008; 7 weeks after finishing extreme events), aboveground biomass was harvested. Plant material was dried in the oven at $70{ }^{\circ} \mathrm{C}$ for $48 \mathrm{~h}$ before being weighed.

To assess the performance of the focal species, the number of leaves of each individual was recorded just before, 2, 4, and 6 weeks after planting them into the community. Seedling mortality was recorded at each time point. Seven weeks after introduction, the seedlings were harvested, dried at $70{ }^{\circ} \mathrm{C}$ for $48 \mathrm{~h}$, and aboveground biomass was determined. The number of 
germinated seeds of the focal species was recorded at the time of harvest.

Data analysis

Data were analyzed by means of the statistical software $\mathrm{R}$ (version 2.7.0 for Mac OS X, R Foundation for Statistical Computing, Vienna, AT). Community cover was analyzed by linear mixed effect models with the random factor "pot" nested in block. Data collected before beginning the extreme event treatments were analyzed separately with the fixed factors temperature, extreme event, and their interaction. The remaining data were analyzed with the additional fixed factors "focal species" and "time" and all interactions. Final biomass was $\log$ transformed and then analyzed with the same model but without the factor time.

The three focal species pairs were analyzed separately using means of the three individuals per pot (or $<3$ in case of seedling mortality; $n=24$ pots). Logtransformed biomass and the germination rate $(\%)$ of seeds were analyzed by means of linear models, and the final number of leaves by a generalized linear model with a Poisson family. Mortality of the transplanted seedlings was analyzed by means of a mixed effects logistic regression model with the random factors "position in pot" (centre/edge) nested in pot. All models included the fixed effects "block," "temperature," "extreme event," and "status" (native/ alien), as well as the interactions of the latter three terms. To analyze growth of introduced seedlings over time, regressions were fitted at the pot level for number of leaves against time (weeks 0-6). Linear growth was assumed as these models resulted in higher $r^{2}$ than models with exponential growth. Slopes of these models were then analyzed with a linear model including the factors block, temperature, extreme event, and status. Interactions were dropped from these models because they were never significant.

\section{Results}

Response of plant communities to elevated temperature and extreme events

Before extreme events started, community cover was significantly higher in elevated (mean \pm standard error; $57.64 \pm 2.60 \%$ ) compared to ambient temperature pots
$(37.36 \pm 1.66 \%$; Table 1). Throughout the experiment, cover remained significantly greater in elevated temperature pots; however, differences became less pronounced over time (Fig. 1a). Aboveground community biomass at harvest was not significantly different between elevated and ambient temperature pots (Fig. 1c).

There were differences in cover between pots that would later be subjected to drought, deluge, or control treatments before these treatments began with drought pots having by chance ca. $10 \%$ higher cover than control or deluge pots. After extreme events, the rate of cover increase was lower in drought compared to control and deluge pots, but differences decreased over the 6 weeks (Fig. 1b). Community biomass in pots experiencing drought was significantly lower than in deluge or control pots (Fig. 1d).

The introduced seedlings did not have a significant effect on community cover although pots with no introduced seedlings had a greater biomass than those with alien invaders or native colonizers (mean \pm standard error; $188.89 \pm 9.00 \mathrm{~g}$ compared to $163.37 \pm$ $7.99 \mathrm{~g}$ and $154.77 \pm 5.66 \mathrm{~g}$, respectively).

Establishment of introduced species in plant communities following extreme events

For Bromus, there were no significant effects of warming on the number of leaves or aboveground biomass (Fig. 2a, d). Mortality in elevated temperature pots was higher than in ambient temperature pots (Fig. 2g). Across both Bromus species, establishment of germinated seeds in elevated temperature pots was lower than in ambient temperature pots (Table 2). For Trifolium, the rate of increase in leaf number over time (Fig. 3e), as well as final leaf number and biomass, was higher in ambient temperature pots (Fig. 2b, e), and mortality was lower (Fig. 2h) than in elevated temperature pots. At harvest, Trifolium in ambient temperature pots had established in higher numbers than in elevated temperature pots (Table 2). For the Asteraceae species, there were on average more leaves per plant in ambient than in elevated temperature pots (Fig. 2c), and in elevated temperature pots they lost more leaves over time (Fig. 3f). Biomass of L. serriola in ambient temperature pots was higher than in elevated temperature pots (Fig. 2f). Mortality in elevated temperature pots was higher than in ambient temperature pots for both species (Fig. 2i). 
Table 1 Results of linear mixed models for community cover (as a single measurement immediately before extreme events, and as measurements over time, i.e., in weeks $0-6$, after extreme events) and biomass

\begin{tabular}{|c|c|c|c|c|c|c|c|c|}
\hline \multirow[t]{2}{*}{ Factor } & \multirow[t]{2}{*}{ df } & \multicolumn{2}{|c|}{ Cover before EE } & \multicolumn{3}{|c|}{ Cover after EE } & \multicolumn{2}{|c|}{ Biomass } \\
\hline & & $F$ & $P$ & den. $d f$ & $F$ & $P$ & $F$ & $P$ \\
\hline $\mathrm{T}$ & 1 & 49.28 & $<0.001$ & 53 & 36.62 & $<0.001$ & 0.050 & 0.822 \\
\hline $\mathrm{EE}$ & 2 & 6.088 & 0.004 & 53 & 25.54 & $<0.001$ & 17.50 & $<0.001$ \\
\hline FS & 2 & - & - & 53 & 0.826 & 0.443 & 8.190 & $<0.001$ \\
\hline Time & 1 & - & - & 198 & 780.4 & $<0.001$ & - & - \\
\hline $\mathrm{T} \times \mathrm{EE}$ & 2 & 2.723 & 0.073 & 53 & 2.157 & 0.126 & 2.400 & 0.100 \\
\hline $\mathrm{T} \times \mathrm{FS}$ & 2 & - & - & 53 & 0.257 & 0.774 & 1.860 & 0.165 \\
\hline $\mathrm{EE} \times \mathrm{FS}$ & 4 & - & - & 53 & 0.278 & 0.891 & 0.980 & 0.426 \\
\hline $\mathrm{T} \times$ Time & 1 & - & - & 198 & 25.05 & $<0.001$ & - & - \\
\hline $\mathrm{EE} \times$ Time & 2 & - & - & 198 & 23.60 & $<0.001$ & - & - \\
\hline FS $\times$ Time & 2 & - & - & 198 & 0.356 & 0.701 & - & - \\
\hline $\mathrm{T} \times \mathrm{EE} \times \mathrm{FS}$ & 4 & - & - & 53 & 0.775 & 0.546 & 0.510 & 0.730 \\
\hline $\mathrm{T} \times \mathrm{EE} \times$ Time & 2 & - & - & 198 & 0.536 & 0.586 & - & - \\
\hline $\mathrm{T} \times \mathrm{FS} \times$ Time & 2 & - & - & 198 & 1.300 & 0.275 & - & - \\
\hline $\mathrm{EE} \times \mathrm{FS} \times$ Time & 4 & - & - & 198 & 0.493 & 0.741 & - & - \\
\hline $\mathrm{T} \times \mathrm{EE} \times \mathrm{FS} \times$ Time & 4 & - & - & 198 & 0.673 & 0.612 & - & - \\
\hline
\end{tabular}

$T$ Temperature, EE Extreme event, $F S$ Focal species, $d f$ Degrees of freedom, $F$ and $P$ values indicated for all fixed effects and interactions. Den.df are indicated for cover after EE; for cover before EE den.df $=65$, for biomass den.df $=54$ for all factors

Significant values $(P<0.05)$ are in bold

Extreme events had no significant effects on the performance of Bromus spp. seedlings, but establishment from seed was greater in drought pots than in deluge or control pots (Table 2). The biomass of Trifolium spp. was significantly greater in drought pots (mean \pm standard error; $0.30 \pm 0.04 \mathrm{~g}$ ) compared to deluge $(0.20 \pm 0.04 \mathrm{~g})$ and control $(0.17 \pm 0.03 \mathrm{~g})$ pots (Table 3 ). The rate of increase in leaf number was higher in drought than in control or deluge treatments. Extreme events did not have a significant effect on the performance of the Asteraceae species (Table 3) although mortality was $32 \%$ in control pots compared to $18 \%$ in deluge and $8 \%$ in drought pots.

Differences in response of native and alien introduced species

While there were no differences between $B$. erectus (native) and $B$. inermis (alien) in biomass or the final number of leaves, $B$. inermis had a faster rate of increase in leaf number than $B$. erectus (Fig. 3a). Mortality of $B$. inermis was four times greater than of $B$. erectus (Fig. 2g). Final seed establishment was higher for B. inermis than for B. erectus (Table 2).
There was only one significant difference in performance between the Trifolium species: the rate of increase in leaf number was higher for T. hybridum (alien) than for T. pratense (native) (Fig. 3b).

After controlling for initial number of leaves, number of leaves did not differ between $L$. serriola (native) and $C$. canadensis (alien). Biomass of $L$. serriola was much higher than of $C$. canadensis (Fig. 2f). The mortality of the Asteraceae species was greater than for Bromus or Trifolium and greater for the alien than the native Asteraceae (Fig. 2i). Germination of $C$. canadensis failed completely, and averaged only $2 \%$ for $L$. serriola (Table 2 ).

\section{Discussion}

Response of plant communities to elevated temperature and extreme events

The positive effect of warming on plant communities, as has been found in many studies (e.g., Penuelas et al. 2004), and negative effect of drought (e.g., Llorens et al. 2004), are in line with our first hypothesis. 
Fig. 1 The development of community cover over time and biomass at harvest (means \pm standard errors). a and c compare elevated versus ambient temperature pots. $\mathbf{b}$ and $\mathbf{d}$ compare extreme events.

$T$ Temperature, $W$ Weeks,

EE Extreme events.

- $P<0.1$, * $P<0.05$,

** $P<0.01$,

*** $P<0.001$, n.s. not

significant
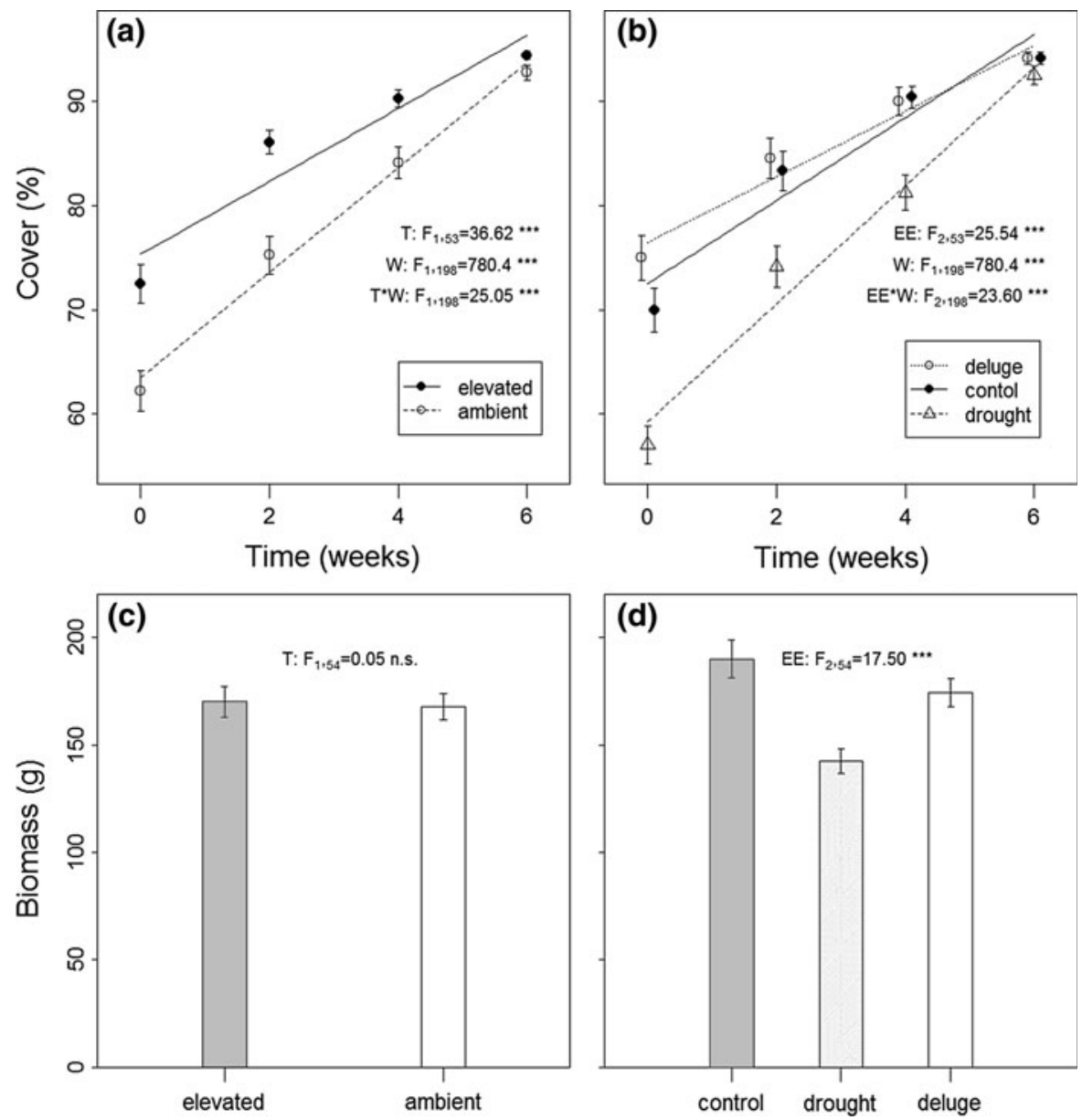

However, greater cover notwithstanding, as in other studies (e.g., Filella et al. 2004; Gordon et al. 1999) we found no overall positive effect of warming on aboveground biomass. This may be because while elevated temperature accelerates early shoot growth (Gordon et al. 1999) over the duration of the experiment the plants grown under ambient temperature reached similar sizes.

A three week long drought had severe negative impacts on the plant communities. Although effects on community cover were short term, the biomass of droughted pots was lower at the time of harvest, as found in other studies (Filella et al. 2004; Grime et al. 2000; Koc 2001). An increased effect of temperature and drought combined (Sternberg et al. 1999) could not be observed, perhaps because in this experiment the temperature increase was not very high. The extreme rainfall treatment did not reduce plant community performance significantly compared to the control. In fact if a deluge is not severe, plants may profit from increased water availability by increasing photosynthesis (Gillespie and Loik 2004). Additional rainfall has been shown to increase total cover (Morecroft et al. 2004; Sternberg et al. 1999) and biomass (White et al. 2000) of plant communities. This was not the case in this study: biomass of deluge pots was intermediate, maybe due to a higher amount of dead aboveground biomass near ground level. While the presence of the focal species did have a significant effect on community biomass (but not on cover), it is uncertain whether this is an effect of competition or disturbance due to transplantation of seedlings. The effects of extreme events on communities in this study are, however, independent of the presence of the focal species, as there was no significant interaction between extreme events and focal species, confirming that the act of introducing the focal species itself did not influence our results. 

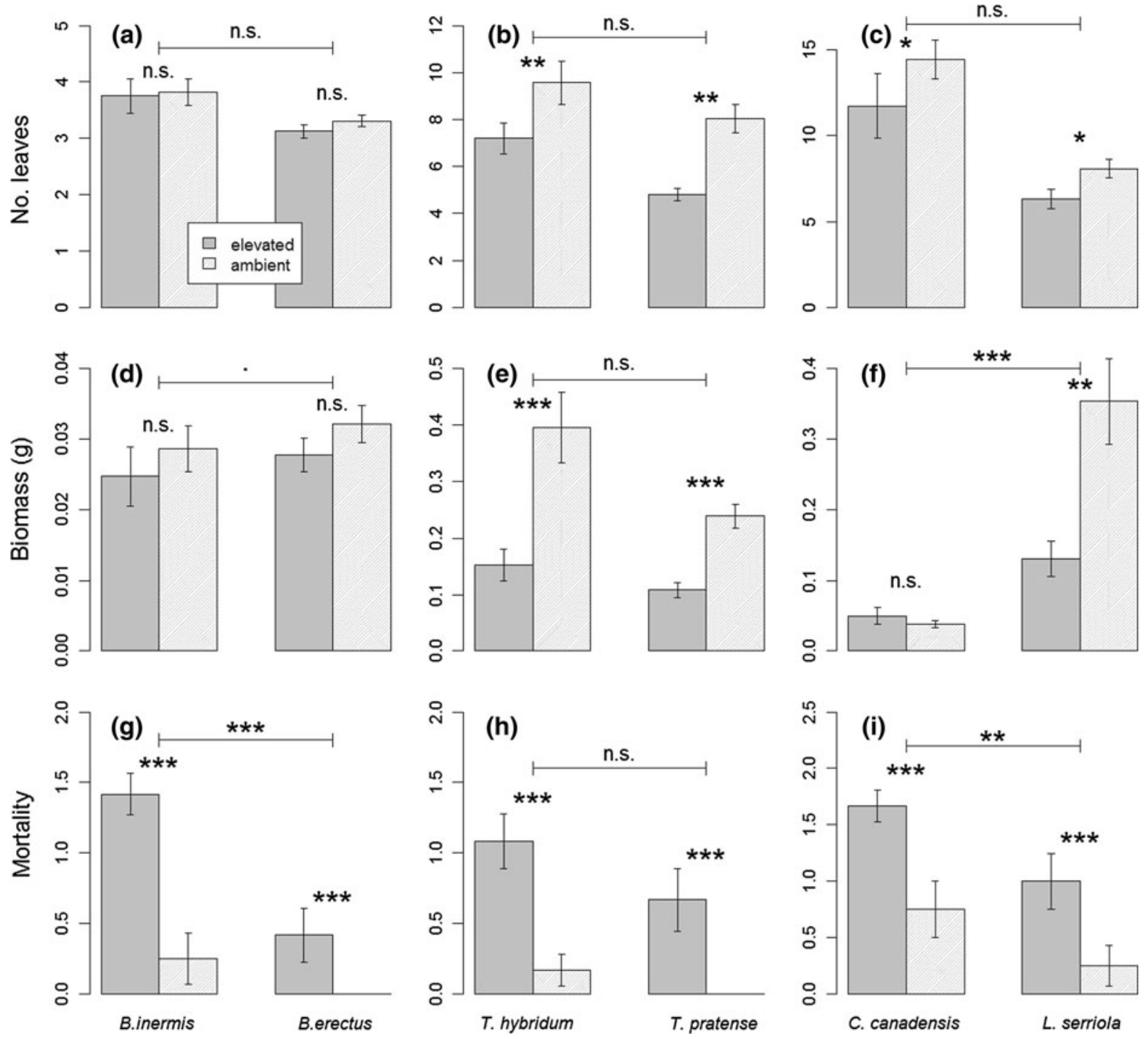

Fig. 2 Number of leaves, biomass, and mortality (number of dead seedlings per pot) of the focal species at harvest. Means \pm standard errors $(n=12)$ are shown for ambient (light gray) and elevated (dark gray) temperature pots averaged over

Overall, this study supports the suggestion that some extreme events rather than temperature increase will have the most severe effects on native plant communities (Jentsch et al. 2007; Nicholls 1995; Wigley 1985). However, the effect of warming might be lower in this study compared to other studies that applied a three times greater $\left(1^{\circ} \mathrm{C}\right)$ increase in temperature. Furthermore, elevated temperature pots may have experienced reduced photosynthetically active radiation on cloudy days due to the surrounding foil. Finally, because growth was cut short by all three extreme event treatments. a, $\mathbf{d}$, and $\mathbf{g}$ are the results for Bromus. b, e, and $\mathbf{h}$ for Trifolium and $\mathbf{c}, \mathbf{f}$, and $\mathbf{i}$ for the Asteraceae. ${ }^{\prime} P<0.1, * P<0.05$, ** $P<0.01$, *** $P<0.001$, n.s. not significant (see Table 3 for statistics)

harvesting, warming effects could not be expressed as a prolongation of the growing season. For the effects of extreme events, it is important to distinguish among types of extreme events; while droughts may have severe negative effects, extreme rainfall may actually have some positive effects. Responses, however, may vary according to season, species, functional composition, and successional status of communities (Gordon et al. 1999; Grime et al. 2000; Penuelas et al. 2004). These factors were controlled in this experiment, whereas they will vary in natural 
plant communities, which will lead to more variable responses to extreme events and resilience in natural compared to experimental settings. While this study shows that short-term effects of extreme events do occur, long-term effects should be investigated with observations over several years, both in experimental and natural systems. It has also been suggested that additional extreme events could amplify negative effects (Crawley 1987).

Establishment of introduced species in plant communities following extreme events

Our data support the hypothesis that introduced plants perform better in communities that have been impacted by some types of extreme events although the focal species did not benefit from the elevated temperature. The greater mortality of the focal species in elevated temperature pots suggests that positive effects of warming on community density increase the potential for competitive exclusion by resident species. This apparently overrides any potential positive effect of temperature on the establishment of the introduced species. Accordingly, more seedlings died in the center of the pots, where the community was usually densest and few gaps occurred (Sheppard, pers. obs.). Of the surviving plants, performance was species specific, with Trifolium and the Asteraceae species being more successful under ambient temperature, at both the germination and juvenile life stages. Bromus, while showing no differences in seedling performance, had higher seed germination under ambient temperature.

This experiment only partly substantiates the hypothesis that increased droughts, floods, and other extreme events are likely to result in opportunities for introduced species to invade (Thuiller et al. 2007). Drought-treated pots posed some advantages for the establishment of the focal species, especially for Trifolium. A severe drought that damages the resident community might increase its invasibility by creating empty spaces, and therefore opportunities for new seedlings to establish (Davis et al. 2000). Trifolium, in particular, performed well in drought pots, which might be because it is not dependent on the soil nitrogen supply since resistance to drought is sometimes positively correlated with nutrient stress tolerance (Macgillivray et al. 1995). A study of a Swiss grassland showed that many graminoid species were 

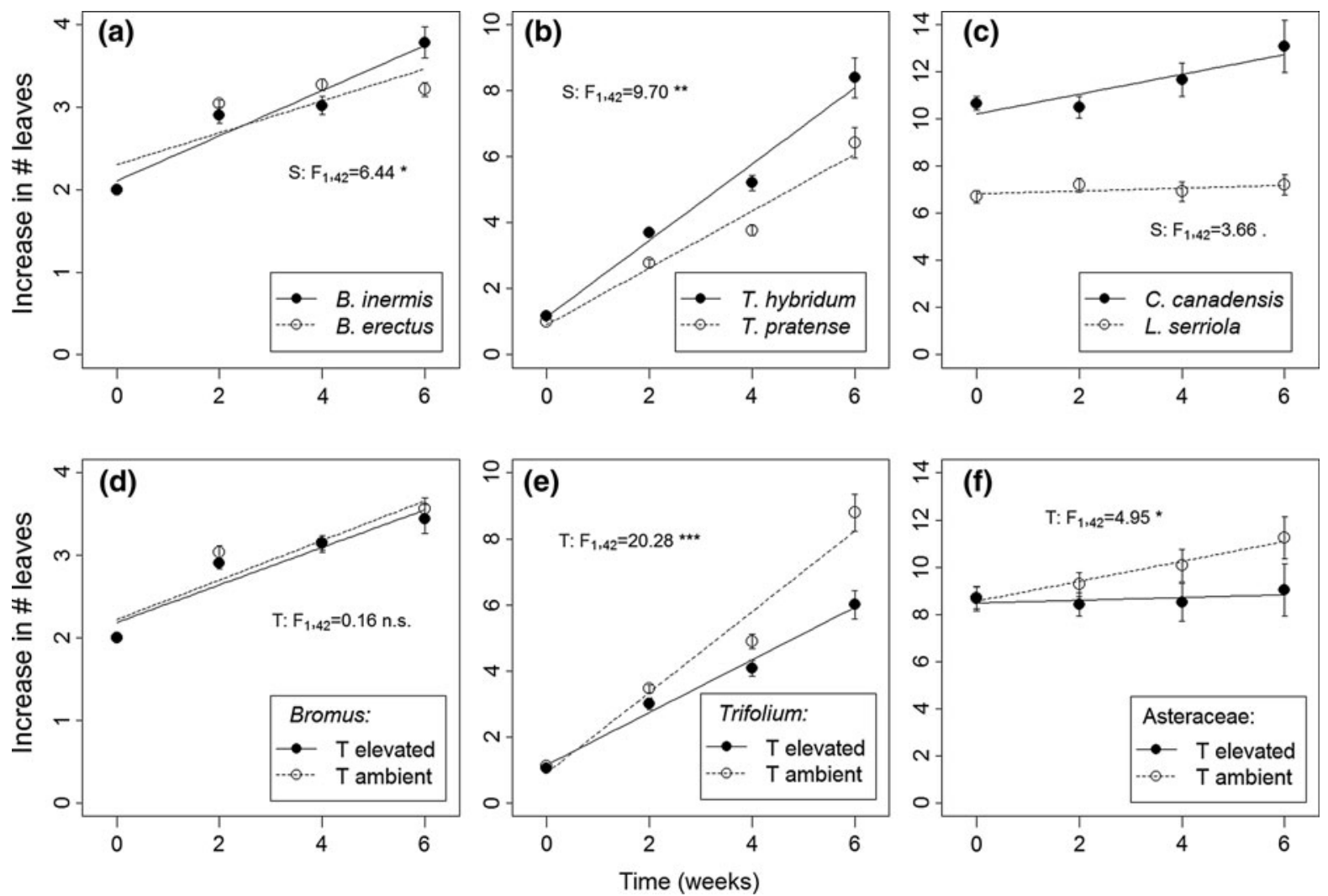

Fig. 3 Increase in the number of leaves of the focal species over 6 weeks (means \pm standard errors). a and $\mathbf{d}$ show results for Bromus, $\mathbf{b}$ and $\mathbf{e}$ for Trifolium, and $\mathbf{c}$ and $\mathbf{f}$ for the Asteraceae. The top row, a-c compare alien versus native seedlings, and the

replaced by a large number of forbs after an extreme drought. Invasions of new species also became more likely (Stampfli and Zeiter 2004). In contrast to drought, deluge did not affect the establishment and performance of the focal species, perhaps because it did not affect the community to a great extent. It appears that the species selected here cannot take advantage of increased water availability, unlike other invasive species for which flooding creates optimal conditions to establish (Truscott et al. 2006). Other studies confirmed that responses to increased precipitation associated with climate change are species specific (Gillespie and Loik 2004).

Differences in the response of native and alien introduced species

Our data cast doubt on the hypothesis that alien invader species will perform better than native species bottom row, $\mathbf{d}-\mathbf{f}$ compare elevated versus ambient temperature for all seedlings. $S$ Status, $T$ Temperature. ${ }^{\bullet} P<0.1,{ }^{*} P<0.05$, ** $P<0.01$, *** $P<0.001$, n.s. not significant

following extreme events or climate warming although one must be cautious to generalize from this sample of three species pairs. Overall, the native colonizers were more resistant and performed better following disturbances in this experiment. As the alien species chosen in this experiment are the most widespread in Switzerland (Becker et al. 2005), they would be expected to perform well. However, few studies have shown universally superior performance of the alien species across all growing conditions when comparing alien-native species pairs (Daehler 2003). No single trait can explain the invasion success of all species, but the traits of successful aliens strongly depend on habitat context (Thompson et al. 1995) and functional traits of the native species present (MacDougall et al. 2006). Aliens often have a greater total leaf area (Thompson et al. 1995) and accordingly we found a higher increase in the number of leaves over time in the alien species across all species pairs. 
Table 3 ANOVA table for various indicators of performance of focal species

\begin{tabular}{|c|c|c|c|c|c|c|c|c|c|c|c|c|}
\hline \multirow[t]{2}{*}{ Factor } & \multirow[t]{2}{*}{ df } & \multicolumn{3}{|c|}{ Final \# leaves } & \multicolumn{2}{|c|}{$\begin{array}{l}\text { Rate of increase } \\
\text { in \# leaves }\end{array}$} & \multicolumn{2}{|c|}{ Biomass } & \multicolumn{2}{|c|}{ Mortality } & \multicolumn{2}{|c|}{$\%$ germination } \\
\hline & & res.df & $\chi^{2}$ & $P$ & $F$ & $P$ & $F$ & $P$ & $F$ & $P$ & $F$ & $P$ \\
\hline \multicolumn{13}{|l|}{ Bromus } \\
\hline Block & 1 & 46 & 1.224 & 0.269 & 9.272 & 0.004 & 12.49 & 0.001 & 0.158 & 0.693 & 1.670 & 0.205 \\
\hline Initial size & 1 & - & - & - & - & - & - & - & - & - & - & - \\
\hline $\mathrm{T}$ & 1 & 45 & 0.054 & 0.817 & 0.158 & 0.693 & 2.729 & 0.108 & 83.38 & $<0.001$ & 66.67 & $<0.001$ \\
\hline $\mathrm{EE}$ & 2 & 43 & 0.038 & 0.963 & 0.328 & 0.722 & 0.053 & 0.948 & 1.103 & 0.341 & 3.420 & 0.044 \\
\hline Stat & 1 & 42 & 1.113 & 0.291 & 6.442 & 0.015 & 3.031 & 0.090 & 45.55 & $<0.001$ & 13.23 & $<0.001$ \\
\hline $\mathrm{T} \times \mathrm{EE}$ & 2 & 40 & 0.042 & 0.959 & - & - & 0.372 & 0.692 & - & - & 0.368 & 0.695 \\
\hline $\mathrm{T} \times$ Stat & 1 & 39 & 0.015 & 0.903 & - & - & 0.155 & 0.697 & - & - & 0.005 & 0.944 \\
\hline $\mathrm{EE} \times$ Stat & 2 & 37 & 0.001 & 0.999 & - & - & 0.251 & 0.780 & - & - & 0.158 & 0.855 \\
\hline $\mathrm{T} \times \mathrm{EE} \times$ Stat & 2 & 35 & 0.003 & 0.973 & - & - & 1.933 & 0.160 & - & - & 0.375 & 0.690 \\
\hline \multicolumn{13}{|l|}{ Trifolium } \\
\hline Block & 1 & 46 & 0.000 & 0.986 & 0.024 & 0.878 & 0.066 & 0.799 & 3.302 & 0.076 & 15.08 & $<0.001$ \\
\hline Initial size & 1 & 45 & 10.48 & 0.001 & - & - & - & - & - & - & - & - \\
\hline $\mathrm{T}$ & 1 & 44 & 8.742 & 0.003 & 20.28 & $<0.001$ & 31.67 & $<0.001$ & 38.52 & $<0.001$ & 45.43 & $<0.001$ \\
\hline $\mathrm{EE}$ & 2 & 42 & 2.480 & 0.084 & 5.650 & 0.007 & 6.239 & 0.005 & 2.693 & 0.079 & 2.719 & 0.080 \\
\hline Stat & 1 & 41 & 2.297 & 0.130 & 9.701 & 0.003 & 2.443 & 0.127 & 0.606 & 0.441 & 1.391 & 0.246 \\
\hline $\mathrm{T} \times \mathrm{EE}$ & 2 & 39 & 0.472 & 0.624 & - & - & 0.700 & 0.503 & - & - & 2.287 & 0.117 \\
\hline $\mathrm{T} \times$ Stat & 1 & 38 & 1.784 & 0.182 & - & - & 0.368 & 0.548 & - & - & 1.391 & 0.246 \\
\hline $\mathrm{EE} \times$ Stat & 2 & 36 & 0.895 & 0.409 & - & - & 1.837 & 0.174 & - & - & 0.006 & 0.994 \\
\hline $\mathrm{T} \times \mathrm{EE} \times$ Stat & 2 & 34 & 0.073 & 0.930 & - & - & 0.188 & 0.830 & - & - & 2.001 & 0.150 \\
\hline \multicolumn{13}{|l|}{ Asteraceae } \\
\hline Block & 1 & 46 & 0.654 & 0.419 & 0.130 & 0.721 & 0.174 & 0.679 & 5.588 & 0.023 & 0.826 & 0.376 \\
\hline Initial size & 1 & 45 & 55.97 & $<0.001$ & - & - & - & - & - & - & - & - \\
\hline $\mathrm{T}$ & 1 & 44 & 6.281 & 0.012 & 4.945 & 0.032 & 6.518 & 0.015 & 21.34 & $<0.001$ & 3.012 & 0.101 \\
\hline $\mathrm{EE}$ & 2 & 42 & 0.579 & 0.560 & 0.261 & 0.772 & 0.018 & 0.982 & 12.46 & $<0.001$ & 2.261 & 0.135 \\
\hline Stat & 1 & 41 & 0.151 & 0.697 & 3.662 & 0.063 & 43.54 & $<0.001$ & 7.530 & 0.009 & - & - \\
\hline $\mathrm{T} \times \mathrm{EE}$ & 2 & 39 & 1.030 & 0.357 & - & - & 0.824 & 0.447 & - & - & 1.988 & 0.168 \\
\hline $\mathrm{T} \times$ Stat & 1 & 38 & 0.016 & 0.900 & - & - & 3.434 & 0.072 & - & - & - & - \\
\hline $\mathrm{EE} \times$ Stat & 2 & 36 & 0.497 & 0.608 & - & - & 0.106 & 0.900 & - & - & - & - \\
\hline $\mathrm{T} \times \mathrm{EE} \times$ Stat & 2 & 34 & 1.710 & 0.181 & - & - & 1.865 & 0.170 & - & - & - & - \\
\hline
\end{tabular}

Final number of leaves was analyzed with a Poisson generalized linear model, and residual df (res.df) are indicated. Rates of increase in leaf number, biomass and \% germination were analyzed with linear models; res.df $=42$ (rates of increase), res.df $=35$ (biomass, seeds; for the Asteraceae, tests for germination are for $L$. serriola only, with res.df $=17$ ). Mortality was analyzed with a generalized linear mixed-effects model (res.df = 42). T Temperature, EE Extreme event, FS Focal species, Stat Status

Significant values $(P<0.05)$ are in bold

Natives have been shown to be favored when resource availability (nutrients, water, or light) is low, and to have higher survival (Daehler 2003). Competition greatly reduces invasive species biomass, suggesting that alien plants are adapted to non-competitive environments in which rapid growth and high reproduction is an advantage (Blumenthal and Hufbauer
2007). Competition, along with biotic resistance, was high in our study, where community cover reached an average of $94 \%$ by the end of the experiment. The focal species had only one chance to establish although in nature the invasibility of a community fluctuates over time (Davis et al. 2000). Even introduced species that become invasive have often 
previously failed in multiple introductions (Sax and Brown 2000). In general, the performance of the introduced species was determined more by functional group than by native or alien status. The leguminous introduced species performed best, and also the legumes included as matrix species in the communities expanded from $5 \%$ cover to on average more than $50 \%$ cover before harvest. This might be related to the advantage of nitrogen fixation in the competitive, disturbed conditions experienced in this experiment.

In conclusion, the often expected fundamental advantage of alien species was not supported in our study, where invasion by alien plants appears not to be distinct from the normal processes of colonization and succession by native species (Thompson et al. 2001). However, the native species chosen for this experiment are all invaders themselves in other parts of the world, which might explain why they performed as well as the alien species (van Kleunen et al. 2010). The alien species in this study also originate from similar latitudes (Eastern Europe, Eurasia, and North America) as the introduced area-invaders from other latitudes with warmer, drier climates might be better able to take advantage of the conditions simulated here (Vilà et al. 2007).

This study suggests that invasion success is likely to be influenced more by indirect effects of climate change on native vegetation than by direct effects on the invasive species themselves. In some cases, climate change and especially extreme events might have large impacts on plant invasions; future research should focus on which conditions and for which species profound changes are expected. Only then early measures can be taken to mitigate negative impacts of plant invasions and climate change.

Acknowledgments We would like to thank Martin Fotsch, Marilyn Gaschen, Markus Hofbauer, and Gurbir Singh Bhullar for their field assistance.

\section{References}

Alpert P (2006) The advantages and disadvantages of being introduced. Biol Invasions 8(7):1523-1534

Becker T, Dietz H, Billeter R, Buschmann H, Edwards PJ (2005) Altitudinal distribution of alien plant species in the Swiss Alps. Perspect Plant Ecol Evol Syst 7(3):173-183

Blumenthal DM, Hufbauer RA (2007) Increased plant size in exotic populations: a common-garden test with 14 invasive species. Ecology 88:2758-2765
Braun-Blanquet J (1964) Pflanzensoziologie. Springer, Wien, New York

Burns JH (2006) Relatedness and environment affect traits associated with invasive and noninvasive introduced Commelinaceae. Ecol Appl 16(4):1367-1376

Crawley MJ (1987) What makes a community invasible? In: Gray AJ, Crawley MJ, Edwards PJ (eds) Colonization, succession and stability. Blackwell, Oxford, pp 429-453

Daehler CC (2003) Performance comparisons of co-occurring native and alien invasive plants: implications for conservation and restoration. Ann Rev Ecol Evol Syst 34:183-211

Davis MA, Grime JP, Thompson K (2000) Fluctuating resources in plant communities: a general theory of invasibility. J Ecol 88(3):528-534

Davis MA, Chew MK, Hobbs RJ et al (2011) Don't judge species on their origins. Nature 474:153-154

Dukes JS, Mooney HA (1999) Does global change increase the success of biological invaders? Trends Ecol Evol 14(4): 135-139

Falk-Petersen J, Bøhn T, Sandlund OT (2006) On the numerous concepts in invasion biology. Biol Invasions 8:1409-1424

Filella I, Penuelas J, Llorens L, Estiarte M (2004) Reflectance assessment of seasonal and annual changes in biomass and $\mathrm{CO}_{2}$ uptake of a mediterranean shrubland submitted to experimental warming and drought. Remote Sens Environ 90(3):308-318

Gillespie IG, Loik ME (2004) Pulse events in great basin desert shrublands: physiological responses of Artemisia tridentata and Purshia tridentata seedlings to increased summer precipitation. J Arid Environ 59(1):41-57

Gordon C, Woodin SJ, Alexander IJ, Mullins CE (1999) Effects of increased temperature, drought and nitrogen supply on two upland perennials of contrasting functional type: Calluna vulgaris and Pteridium aquilinum. New Phytol 142(2):243-258

Grime JP, Brown VK, Thompson K et al (2000) The response of two contrasting limestone grasslands to simulated climate change. Science 289(5480):762-765

IPCC (2007) Climate change 2007: the physical science basis. Contribution of working group I to the fourth assessment report of the Intergovernmental Panel on Climate Change. Cambridge University Press, Cambridge, New York

Jentsch A, Kreyling J, Beierkuhnlein C (2007) A new generation of climate-change experiments: events, not trends. Front Ecol Environ 5(7):365-374

Koc A (2001) Autumn and spring drought periods affect vegetation on high elevation rangelands of Turkey. J Range Manage 54(5):622-627

Lambertini M, Leape J, Marton-Levèvre J et al (2011) Invasives: a major conservation threat. Science 333:404-405

Laubner K, Wagner G (2001) Flora Helvetica, 3rd edn. Verlag Paul Haupt, Bern

Le Roux PC, McGeoch MA, Nyakatya MJ, Chown SL (2005) Effects of a short-term climate change experiment on a subantarctic keystone plant species. Glob Change Biol 11(10): 1628-1639

Llorens L, Penuelas J, Estiarte M, Bruna P (2004) Contrasting growth changes in two dominant species of a mediterranean shrubland submitted to experimental drought and warming. Ann Bot 94(6):843-853 
MacDougall AS, Boucher J, Turkington R, Bradfield GE (2006) Patterns of plant invasion along an environmental stress gradient. J Veg Sci 17(1):47-56

Macgillivray CW, Grime JP, Band SR et al (1995) Testing predictions of the resistance and resilience of vegetation subjected to extreme events. Funct Ecol 9(4):640-649

Meusel H, Jäger EJ (1992) Vergleichende Chorologie der zentraleuropäischen Flora. Fischer, Jena

Morecroft MD, Masters GJ, Brown VK, Clarke IP, Taylor ME, Whitehouse AT (2004) Changing precipitation patterns alter plant community dynamics and succession in an ex-arable grassland. Funct Ecol 18(5):648-655

Nicholls N (1995) Long-term climate monitoring and extreme events. Climatic Change 31(2-4):231-245

Penuelas J, Gordon C, Llorens L et al (2004) Nonintrusive field experiments show different plant responses to warming and drought among sites, seasons, and species in a north-south European gradient. Ecosystems 7(6):598-612

Petryna L, Moora M, Nunes CO, Cantero JJ, Zobel M (2002) Are invaders disturbance-limited? Conservation of mountain grasslands in Central Argentina. Appl Veg Sci 5(2): 195-202

Sax DF, Brown JH (2000) The paradox of invasion. Global Ecol Biogeogr 9(5):363-371

Stampfli A, Zeiter M (2004) Plant regeneration directs changes in grassland composition after extreme drought: a 13-year study in southern Switzerland. J Ecol 92(4):568-576

Sternberg M, Brown VK, Masters GJ, Clarke IP (1999) Plant community dynamics in a calcareous grassland under climate change manipulations. Plant Ecol 143(1):29-37

Sutherst RW (2000) Climate change and invasive species: a conceptual framework. In: Mooney HA, Hobbs RJ (eds)
Invasive species in a changing world. Island Press, Washington, DC, pp 211-240

Thompson K, Hodgson JG, Rich TCG (1995) Native and alien invasive plants: more of the same? Ecography 18(4): 390-402

Thompson K, Hodgson JG, Grime JP, Burke MJW (2001) Plant traits and temporal scale: evidence from a 5-year invasion experiment using native species. J Ecol 89(6):1054-1060

Thuiller W, Richardson DM, Midgley GF (2007) Will climate change promote alien plant invasions? Ecol Stud 193: 197-211

Truscott AM, Soulsby C, Palmer SCF, Newell L, Hulme PE (2006) The dispersal characteristics of the invasive plant Mimulus guttatus and the ecological significance of increased occurrence of high-flow events. J Ecol 94(6): 1080-1091

van Kleunen M, Dawson W, Schlaepfer D, Jeschke JM, Fischer M (2010) Are invaders different? A conceptual framework of comparative approaches for assessing determinants of invasiveness. Ecol Lett 13:947-958

Vilà M, Corbin JD, Dukes JS, Pino J, Smith SD (2007) Linking plant invasions to global environmental change. In: Canadell JG, Pataki DE, Pitelka LF (eds) Terrestrial ecosystems in a changing world. Springer, Berlin, pp 93-102

White TA, Campbell BD, Kemp PD, Hunt CL (2000) Sensitivity of three grassland communities to simulated extreme temperature and rainfall events. Glob Change Biol 6(6): 671-684

Wigley TML (1985) Impact of extreme events. Nature 316(6024): 106-107 